\title{
Price-Level Targeting and Stabilization Policy
}

\begin{abstract}
Aleksander Berentsen and Christopher J. Waller
The authors construct a dynamic stochastic general equilibrium model to study optimal monetary stabilization policy. Prices are fully flexible and money is essential for trade. The authors' main result is that if the central bank pursues a price-level target, it can control inflation expectations and improve welfare by stabilizing short-run shocks to the economy. The optimal policy involves smoothing nominal interest rates that effectively smooths consumption across states.(JEL E41, E52)
\end{abstract}

Federal Reserve Bank of St. Louis Review, March/April 2013, 95(2), pp. 145-63.

A key objective of modern central banking is to keep inflation low and stable over some long time horizon. However, central banks are also concerned with stabilizing the real economy in the short run. Balancing these two objectives is a complex policy task for central bankers and thus there is an obvious need for economic models to guide central bankers in making informed policy choices.

After a long period of inactivity, the last decade has seen a tremendous resurgence of research focusing on how to conduct stabilization policy in the face of temporary shocks when there is a desire to keep inflation low and stable in the long run. Nearly, all of this work has come from the New Keynesian (NK) literature that, in the tradition of real business cycle models, constructs dynamic stochastic general equilibrium models to study optimal stabilization policy. What separates NK models from real business cycle models is their reliance on nominal rigidities, such as price or wage stickiness, that allows monetary policy to have real effects. A key policy recommendation coming out of NK models is that "good" monetary policy requires guiding inflation expectations in an appropriate manner. $\frac{1}{\text { In }}$ order to do so, it is often advocated that the central

Aleksander Berentsen is a professor of economic theory at the University of Basel, Switzerland. Christopher J. Waller is senior vice president and director of research at the Federal Reserve Bank of St. Louis. The authors have received many beneficial comments from many people. In particular, they thank two anonymous referees, Gaudi Eggertsson, and the participants at the Liquidity in Frictional Markets conference at the Federal Reserve Bank of Cleveland, November 14-15, 2008. Much of the paper was written while Aleksander Berentsen was visiting the University of Pennsylvania. The authors also thank the Federal Reserve Bank of Cleveland, the Center for Economic Studies in Munich, and the Kellogg Institute at the University of Notre Dame for research support.

This article is reprinted from the Journal of Money, Credit, and Banking, October 2011, 43(7, Suppl.), pp. 559-80. Copyright @ 2011. The Ohio State University. Reprinted with permission.

(c) 2013, The Federal Reserve Bank of St. Louis. The views expressed in this article are those of the author(s) and do not necessarily reflect the views of the Federal Reserve System, the Board of Governors, or the regional Federal Reserve Banks. Articles may be reprinted, reproduced, published, distributed, displayed, and transmitted in their entirety if copyright notice, author name(s), and full citation are included. Abstracts, synopses, and other derivative works may be made only with prior written permission of the Federal Reserve Bank of St. Louis. 


\section{Berentsen and Waller}

bank adopt some version of a price-level target or an inflation target. It is still an open question as to which one is the better targeting approach.

NK models typically are "cashless" in the sense that there are no monetary trading frictions. Instead, the driving friction is some type of nominal rigidity but there has been considerable debate as to what nominal object should be rigid (output price, input price, or nominal wage) as well as how the rigidity occurs (Calvo, Taylor, menu cost).

In this paper, we sidestep the debate over nominal rigidity and take the opposite approachwe study stabilization policy in a model where all prices are flexible but there are trading frictions that money overcomes. $\underline{2}$ We construct a dynamic stochastic general equilibrium model where

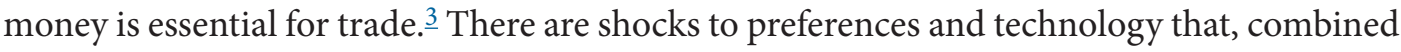
with the monetary friction, give rise to welfare-improving interventions by the central bank. The existence of a credit sector generates a nominal interest rate that the monetary authority manipulates in its attempt to stabilize these shocks.

We demonstrate that the critical element for effective stabilization policy is the central bank's control of long-run inflation expectations via price-level targeting. By doing so, monetary policy has real effects even though prices are fully flexible-a prescription similar to that of NK models. Whereas managing inflation expectations makes a central bank's stabilization response to aggregate shocks more effective in the NK models, our model makes a much stronger case for managing expectations-failure to do so makes stabilization policy completely neutral. Thus, the idea that the central bank needs to "manage inflation expectations" is good advice regardless of whether or not there are nominal rigidities in the economy.

Stabilization policy in our model works through a liquidity effect. By injecting money, the central bank lowers nominal interest rates, stimulating borrowing, which leads to higher consumption and production even though prices are perfectly flexible. This works without causing current inflation because the central bank commits to undo any current monetary injections at some future date to bring prices back to the long-run price path. By returning to the announced price path at a specified date, the central bank pins down the real value of money at that date. In our model, there are agents who sell goods today for cash, which is used for future spending and consumption. By working backward, sellers today know that the current injection has no future inflation implications and any money received today has a certain value in the future. Hence, sellers do not adjust their prices one for one with the injections of cash today. As a result, real balances increase as do consumption and production. The characteristic feature of the optimal stabilization policy under price-level targeting is the smoothing of nominal interest rates and consumption across states.

It is critical that the central bank can commit itself to a price-level path and unravel these current injections at a future date. If sellers perceive the injections are permanent, then they anticipate (correctly) that current injections will lead to higher future prices and raise their current prices one for one with the injections. This leaves the real value of money unchanged and there are no real effects from the injections.

We think this is a relevant story for the situation facing the Federal Reserve after the financial crisis of 2008. Prior to the crisis markets were functioning "normally" with relatively few frictions regarding needs for liquidity. During 2008-09 crisis, there were substantial liquidity frictions affecting financial markets, which in turn affected economic performance. In response 
to the appearance of these frictions, the Fed doubled the size of its balance sheet and the stock of money outstanding. Despite these large injections of liquidity into the system, inflation expectations did not appear to change. Our explanation for this is that agents believed this massive injection of liquidity was temporary and would be reversed when markets began functioning "normally." In short, the Fed would take actions to undo them at a future date. As a result, firms did not increase their prices and the real value of money increased, which presumably had some real effect. At the same time, many stories circulated that markets were concerned the Fed would not unwind these monetary injections in a timely fashion and thus inflation could take off. The Fed undertook great pains to convince markets that they could unwind these injections when needed. This description of the monetary policy events of 2009-09 is perfectly consistent with the policy predictions in our model.

While stabilization policy has been widely studied in NK models, to our knowledge, we are the first to study it in a modern, micro-founded model with flexible prices. There are other models with flexible prices and liquidity effects (such as Grossman and Weiss, 1983, and Fuerst, 1992); but in those models only a subset of agents receives injections of cash (borrowers), whereas in our model, all agents receive injections. This is not a small difference-models in which agents receive differential amounts of money transfers will clearly have real effects, since there is a redistribution of resources across agents. We do not employ this redistribution channel in our environment, yet we still get real effects from monetary injections because of the central bank's commitment to a price-level path. Finally, most of the research using the Fuerst model studies the impact of unexpected innovations of the money supply on nominal interest rates and real variables. These researchers do not study optimal stabilization policy. In our model, the central bank fully reveals its state-contingent plan of interventions (and reversals), so agents are not being "surprised" by policy innovations.

First, we describe the environment. We then derive the first-best allocation. Next we present agents' optimization problems, followed by a discussion of the central bank's stabilization problem. We discuss the results and follow up with our conclusion. All proofs of the propositions have not been published due to space limitations but are available in an earlier working paper available online (Berentsen and Waller, 2009b).

\section{THE ENVIRONMENT}

The basic environment is that of Berentsen, Camera, and Waller (2007), which builds on Lagos and Wright (2005). We use the Lagos-Wright framework because it provides a microfoundation for money demand and it allows us to introduce heterogeneous preferences for consumption and production while keeping the distribution of money balances analytically tractable. Time is discrete and in each period, there are three perfectly competitive markets that open sequentially. ${ }^{4}$ Market 1 is a credit market, while markets 2 and 3 are goods markets. There is a $[0,1]$ continuum of infinitely lived agents and one perishable good produced and consumed by all agents.

At the beginning of the period, agents receive a preference shock such that they either consume, produce, or neither in the second market. With probability $n$ an agent consumes, with probability $s$ he produces, and with probability $1-n-s$ he does neither. We refer to consumers as buyers and producers as sellers. 


\section{Berentsen and Waller}

In the second market, buyers get utility $\varepsilon u(q)$ from $q>0$ consumption, where $\varepsilon$ is a preference parameter and $u^{\prime}(q)>0, u^{\prime \prime}(q)<0, u^{\prime}(0)=+\infty$, and $u^{\prime}(\infty)=0$. Furthermore, we impose that the elasticity of utility $e(q)=\frac{q u^{\prime}(q)}{u(q)}$ is bounded. Producers incur utility cost $c(q) / \alpha$ from producing $q$ units of output, where $\alpha$ is a measure of productivity. We assume that $c^{\prime}(q)>0, c^{\prime \prime}(q) \geq 0$, and $c^{\prime}(0)=0$.

Following Lagos and Wright (2005), we assume that in the third market all agents consume and produce, getting utility $U(x)$ from $x$ consumption, with $U^{\prime}(x)>0, U^{\prime}(0)=\infty, U^{\prime}(+\infty)=0$, and $U^{\prime \prime}(x) \leq 0 . \frac{5}{}$ Agents can produce one unit of the consumption good with one unit of labor that generates one unit of disutility. The discount factor across dates is $\beta=(1+\rho)^{-1} \in(0,1)$, where $\rho$ is the time rate of discount.

\section{Information Frictions, Money, and Credit}

To motivate a role for fiat money, in market 2, our preference structure creates a singlecoincidence problem in which buyers do not have a good desired by sellers. In addition to this single coincidence of wants problem, the following frictions are assumed. First, as in Kocherlakota (1998), due to a lack of record keeping, trading histories of agents in the goods markets are private information, which rules out trade credit between individual buyers and sellers. This implies agents are "anonymous" to each other. Second, there is no public communication of individual trading outcomes (public memory), which in turn eliminates the use of social punishments to support gift-giving equilibria. The combination of these two frictions and the single-coincidence problem implies that sellers require immediate compensation from buyers. In short, there must be immediate settlement with some durable asset and money is the only durable asset in our economy. So, buyers must use money to acquire goods in market 2 . These are the micro-founded frictions that make money essential for trade. In market 3, agents can produce for their own consumption or use money balances acquired earlier. In this market, money is not essential for trade. $\underline{6}$ Thus, market 2 is a market where money has a liquidity premium. Market 3 , on the other hand, is a standard frictionless market where there is no need for a liquid asset.

The first market is a credit market. Almost by definition, credit requires record keeping over private trading histories and nonanonymous transactions. It is exactly this tension that makes it difficult to have money and credit coexist in micro-founded models. Thus, we follow Berentsen, Camera, and Waller (2007) and assume that a limited record-keeping technology exists in market 1 that can keep track of trading histories involving exchanges of one particular objectmoney. This limited record-keeping technology is similar to an ATM-agents can identify themselves to the ATM and either borrow or deposit cash. Agents cannot borrow or deposit goods at the ATM. These cash transactions can be recorded and interest is charged to borrowers and paid to depositors. Thus, while there is record keeping of trading histories over these cash transactions, the ATM has no idea what a borrower does with the cash-there is no record of how the cash is used for buying goods.

We assume that any funds borrowed or lent in market 1 are repaid in market 3 . The nominal interest rate on these loans is denoted by $i$. Given the discrete time aspect of the model, loans are technically "intraperiod" loans but in reality they can be thought of as an interperiod loan. For example, consider a loan taken out at 23:59 on December 31 or one taken out at 00:01 on 
January 1 with both being repaid the following December 31 . The first is an "interperiod" loan and the latter is an "intraperiod" loan. While technically different, there are no serious economic differences between the two loans. Thus, our intraperiod loans should be thought of this way-funds are borrowed early in the period and repaid late in the period.

One can show that due to the quasi-linearity of preferences in market 3 there is no gain from multiperiod contracts. Furthermore, since the aggregate states are revealed prior to contracting, the one-period nominal debt contracts that we consider are optimal. Finally, in all models with credit, default is a serious issue. To focus on optimal stabilization, we simplify the analysis by assuming a mechanism exists that ensures repayment of loans in the third market. ${ }^{7}$

\section{Shocks}

To study the optimal response to shocks, we assume that $n, s, \alpha$, and $\varepsilon$ are stochastic. The random variable $n$ has support $[\underline{n}, \bar{n}] \in(0,1 / 2], s$ has support $[\underline{s}, \bar{s}] \in(0,1 / 2], \alpha$ has support $[\underline{\alpha}, \bar{\alpha}], 0<\underline{\alpha}<\bar{\alpha}<\infty$, and $\varepsilon$ has support $[\underline{\varepsilon}, \bar{\varepsilon}], 0<\underline{\varepsilon}<\bar{\varepsilon}<\infty$. Let $\omega=(n, s, \alpha, \varepsilon) \in \Omega$ be the aggregate state in market 1 , where $\Omega=[\underline{n}, \bar{n}] \times[\underline{s}, \bar{s}] \times[\underline{\alpha}, \bar{\alpha}] \times[\underline{\varepsilon}, \bar{\varepsilon}]$ is a closed and compact subset on $\boldsymbol{R}_{+}^{4}$. The shocks are serially uncorrelated. Let $f(\omega)$ denote the density function of $\omega$.

Shocks to $n$ and $\varepsilon$ are thought of as aggregate demand shocks, while shocks to $s$ and $\alpha$ are aggregate supply shocks. We call shocks to $\varepsilon$ and $\alpha$ intensive margin shocks since they change the desired consumption of each buyer and the productivity of each seller, respectively, without affecting the number of buyers or sellers. In contrast, shocks to $n$ and $s$ affect the number of buyers and sellers. Although we call these aggregate shocks, there are actually sectoral shocks since they do not affect demand or productivity in the third market. Nevertheless, as we see below, output in market 3 is constant so any volatility in total output per period is driven by shocks in market 2 .

\section{Monetary Policy}

Monetary policy has a long- and short-run component. The long-run component focuses on the trend inflation rate. The short-run component is concerned with the stabilization response to aggregate shocks.

We assume a central bank exists that controls the supply of fiat currency. We denote the gross growth rate of the money supply by $\gamma=M_{t} / M_{t-1}$, where $M_{t}$ denotes the per capita money stock in market 3 in period $t$. The central bank implements its long-term inflation goal by providing deterministic lump-sum injections of money, $\tau M_{t-1}$, at the beginning of the period. These transfers are given to the private agents. The net change in the aggregate money stock is given by $\tau M_{t-1}=(\gamma-1) M_{t-1}$. If $\gamma>1$, agents receive lump-sum transfers of money. For $\gamma<1$, the central bank must be able to extract money via lump-sum taxes from the economy. For notational ease, variables corresponding to the next period are indexed by +1 , and variables corresponding to the previous period are indexed by -1 . There is an initial money stock $M_{0}>0$.

Throughout this paper, we will assume that $\gamma$ determines the long-run desired inflation rate and that, for unspecified reasons, $\gamma>\beta$; that is, the central bank does not run the Friedman rule. The inability to run the Friedman rule may occur in environments with limited enforcement. In such environments, all trades must be voluntary and so lump-sum taxes of money are impossible because the central bank cannot impose any penalties on the agents (see Kocherlakota, 2001). $\underline{8}$ 


\section{Berentsen and Waller}

On the other hand, the central bank might not choose to run the Friedman rule because it is not the optimal policy. For example, the Friedman rule can be suboptimal in models that display matching externalities (see Berentsen, Rocheteau, and Shi, 2007, and Rocheteau and Wright, 2005). Another reason the central bank might be constrained from implementing the Friedman rule is that there are seigniorage needs implying $\gamma>1$. Since our focus is stabilization policy, we have not explicitly modeled reasons that give rise to deviations from the Friedman rule. However, we think doing so is an interesting research question to pursue and have done so in a related paper (Berentsen and Waller, 2009a).

The central bank implements its short-term stabilization policy through state-contingent changes in the stock of money. Let $\tau_{1}(\omega) M_{-1}$ and $\tau_{3}(\omega) M_{-1}$ denote the state-contingent cash injections in markets 1 and 3 received by private agents. Note that total injections at the beginning of the period are $T=\left[\tau+\tau_{1}(\omega)\right] M_{-1}$. We assume that $\tau_{1}(\omega)+\tau_{3}(\omega)=0$. In short, any injections in market 1 are undone in market 3 . This effectively means that the long-term inflation rate is still deterministic since $\tau M_{-1}$ is not state dependent. Consequently, changes in $\tau_{1}(\omega)$ affect the money stock in market 2 without affecting the long-term inflation rate in market $3 .{ }^{9}$ With $\tau_{1}(\omega)+\tau_{3}(\omega)=0$, we are implicitly assuming the central bank chooses a path for the money stock in market 3 . As we show later, this means the central bank is engaged in price-level targeting (in terms of market 3 prices) that allows the central bank to control price expectations in market 3 , which is critical for successful stabilization policy.

We will think of our markets 2 and 3 structure in the following way-market 2 is the period where liquidity frictions suddenly come into play and central bank policy can alleviate the economic consequences of these frictions via a temporary change in the supply of liquid assets. Market 3 can be thought of as the economy reverting back to a state of "normalcy" in which frictions disappear and the central bank can reverse its liquidity actions without any effect on prices, output, or interest rates. $\underline{10}$

The state-contingent injections of cash should be viewed as a type of repurchase agreementthe central bank "sells" money in market 1 under the agreement that it is being repurchased in market 3. Alternatively, $\tau_{1}(\omega) M_{-1}$ can be thought of as a zero interest discount loan to households that is repaid in the night market. If $\tau_{1}(\omega)<0$, agents would be required to lend to the central bank at zero interest. Since they can earn interest by lending in the credit market, it is obvious that agents would never lend money to the central bank. Thus, $\tau_{1}(\omega)<0$ is not feasible and so $\tau_{1}(\omega) \geq 0$ in all states. $\underline{11}$ Finally, to ensure repayment of loans, we assume the central bank has the same record-keeping and enforcement technologies as in the credit market. Thus, the only difference between the central bank and the credit market is the ability of the central bank to print fiat currency.

The precise sequence of action after the shocks are observed is as follows. First, the monetary injection $\tau M_{-1}$ occurs and the central bank offers up to $\left.\tau_{1}(\omega)\right] M_{-1}$ units of cash per capita to agents at no cost. Then, agents move to the credit market where nonbuyers lend their idle cash and buyers borrow money. Agents then move on to market 2 and trade goods. In the third market, agents trade goods once again, all financial claims are settled, and the central bank takes out $\left.\left.\tau_{3}(\omega)\right] M_{-1}=-\tau_{1}(\omega)\right] M_{-1}$ units of money. 


\section{FIRST-BEST ALLOCATION}

In a stationary equilibrium, the expected lifetime utility of the representative agent at the beginning of period $t$ is given by

$$
(1-\beta) \mathcal{W}=U(x)-x+\int_{\Omega}\{n \varepsilon u[q(\omega)]-(s / \alpha) c[(n / s) q(\omega)]\} f(\omega) d \omega .
$$

The first-best allocation satisfies

$$
\begin{gathered}
U^{\prime}\left(x^{*}\right)=1 \text { and } \\
\alpha \varepsilon u^{\prime}\left[q^{*}(\omega)\right]=c^{\prime}\left[(n / s) q^{*}(\omega)\right] \text { for all } \omega .
\end{gathered}
$$

These are the quantities chosen by a social planner who could force agents to produce and consume.

\section{MONETARY ECONOMY}

We now study the allocation arising in the monetary economy. In what follows, we look at a representative period $t$ and work backward from the third to the first market to examine the agents' choices.

\section{The Third Market}

In the third market, agents consume $x$, produce $h$, and adjust their money balances taking into account cash payments or receipts from the credit market. If an agent has borrowed $l$ units of money, then he repays $(1+i) l$ units of money.

Consider a stationary equilibrium. Let $V_{1}(m, t)$ denote the expected lifetime utility at the beginning of market 1 with $m$ money balances prior to the realization of the aggregate state $\omega$. Let $V_{3}(m, l, \omega, t)$ denote the expected lifetime utility from entering market 3 with $m$ units of money and net borrowing $l$ when the aggregate state is $\omega$ in period $t$. For notational simplicity, we suppress the dependence of the value functions on the aggregate state and time.

The representative agent's program is

$$
\begin{aligned}
& V_{3}(m, l)=\max _{x, h, m_{+1}}\left[U(x)-h+\beta V_{1,+1}\left(m_{+1}\right)\right] \\
& \text { s.t. } x+\phi m_{+1}=h+\phi\left(m+\tau_{3} M_{-1}\right)-\phi(1+i) l,
\end{aligned}
$$

where $m_{+1}$ is the money taken into period $t+1$. Rewriting the budget constraint in terms of $h$ and substituting into (3) yields

$$
V_{3}(m, l)=\phi\left[m+\tau_{3} M_{-1}-(1+i) l\right]+\max _{x, m_{+1}}\left[U(x)-x-\phi m_{+1}+\beta V_{1}\left(m_{+1}\right)\right] .
$$

The first-order conditions are $U^{\prime}(x)=1$ and

$$
-\phi_{-1}+\beta V_{1}^{m}=0,
$$


where the superscript denotes the partial derivative with respect to the argument $m$. Note that the first-order condition for money has been lagged one period. Thus, $V_{1}^{m}$ is the marginal value of taking an additional unit of money into the first market in period $t$. Since the marginal disutility of working is one, $-\phi_{-1}$ is the utility cost of acquiring one unit of money in the third market of period $t-1$.

The envelope conditions are

$$
V_{3}^{m}=\phi ; V_{3}^{l}=-\phi(1+i)
$$

As in Lagos and Wright (2005), the value function is linear in wealth. The implication is that all agents enter the following period with the same amount of money.

\section{The Second Market}

At the beginning of the second market, there are three trading types: buyers $(b)$, sellers $(s)$, and others $(o)$. Accordingly, let $V_{2 j}(m, l)$ denote the expected lifetime utility of an agent of trading type $j=b, s, o$. Let $q_{b}$ and $q_{s}$, respectively, denote the quantities consumed by a buyer and produced by a seller and let $p_{2}$ be the nominal price of goods in market 2 . Since $j=o$ agents are inactive in this market, we have $V_{20}(m, l)=V_{3}(m, l)$.

A seller who holds $m$ money and $l$ loans at the opening of the second market has expected lifetime utility

$$
V_{2 s}(m, l)=-c\left(q_{s}\right) / \alpha+V_{3}\left(m+p_{2} q_{s}, l\right),
$$

where $q_{s}=\arg \max _{q_{s}}\left[-c\left(q_{s}\right) / \alpha+V_{3}\left(m+p q_{s}, l\right)\right]$. Using (5), the first-order condition reduces to

$$
c^{\prime}\left(q_{s}\right)=\alpha p_{2} \phi=\alpha p_{2} / p_{3}, \quad \omega \in \Omega \text {. }
$$

Sellers decide whether to produce for a unit of money in market 2 or in market 3 . As a result, they compare the productivity cost of producing and acquiring a unit of money in market 2 with the relative cost of producing and acquiring a unit of money in market 3 . Thus, the supply of goods in market 2 is driven by the relative cost of acquiring money across the two markets.

A buyer who has $m$ money and $l$ loans at the opening of the second market has expected lifetime utility

$$
V_{2 b}(m, l)=\varepsilon u\left(q_{b}\right)+V_{3}\left(m-p_{2} q_{b}, l\right),
$$

where $q_{b}=\arg \max _{q_{b}} \varepsilon u\left(q_{b}\right)+V_{3}\left(m-p q_{b}, l\right)$ s.t. $p q_{b} \leq m$. Using (5) and (6), the buyer's first-order condition can be written as

$$
\lambda_{q}=\phi\left[\alpha \varepsilon u^{\prime}\left(q_{b}\right) / c^{\prime}\left(q_{s}\right)-1\right], \omega \in \Omega,
$$

where $\lambda_{q}=\lambda_{q}(\omega)$ is the multiplier on the buyer's budget constraint in state $\omega$. If the budget constraint is not binding, then $\alpha \varepsilon u^{\prime}\left(q_{b}\right)=c^{\prime}\left(q_{s}\right)$, which means trades are efficient. If it is binding, then $\alpha \varepsilon u^{\prime}\left(q_{b}\right)>c^{\prime}\left(q_{s}\right)$, which means trades are inefficient. In this case, the buyer spends all of his money, that is, $p_{2} q_{b}=m$. 
The marginal value of a loan at the beginning of the second market is the same for all agents and so

$$
V_{2 j}^{l}=-(1+i) \phi
$$

for $j=b, s, o$. Using the envelope theorem and equations (5) and (7), the marginal values of money for $j=b$ and $j=s, o$ in the second market are

$$
\begin{gathered}
V_{2 b}^{m}=\phi \alpha \varepsilon u^{\prime}\left(q_{b}\right) / c^{\prime}\left(q_{s}\right), \\
V_{2 s}^{m}=V_{2 o}^{m}=\phi .
\end{gathered}
$$

\section{The First Market}

An agent who has $m$ money at the opening of the first market has expected lifetime utility

$$
V_{1}(m)=\int_{\Omega}\left[n V_{2 b}\left(m_{b}, l_{b}\right)+s V_{2 s}\left(m_{s}, l_{s}\right)+(1-n-s) V_{2 o}\left(m_{o}, l_{o}\right)\right] f(\omega) d \omega,
$$

where $m_{j}=m+T+l_{j}, j=b, s, o$. Once trading types are realized, an agent of type $j=b, s, o$ solves

$$
\max V_{2 j}\left(m_{j}, l_{j}\right) \text { s.t. } 0 \leq m_{j} .
$$

The constraint means that money holdings cannot be negative. The first-order condition is

$$
V_{2 j}^{m}+V_{2 j}^{l}+\lambda_{j}=0, \quad \omega \in \Omega,
$$

where $\lambda_{j}=\lambda_{j}(\omega)$ is the multiplier on the agent's nonnegativity constraint in state $\omega$. It is straightforward to show that buyers will become net borrowers while the others become net lenders. Consequently, we have $\lambda_{b}=0$ and $\lambda_{s}=\lambda_{o}>0$.

Using (8)-(10), the first-order conditions for $j=b$ and for $j=s, o$ can be written as

$$
\begin{gathered}
\alpha \varepsilon u^{\prime}\left(q_{b}\right)=c^{\prime}\left(q_{s}\right)(1+i), \quad \omega \in \Omega, \\
\lambda_{s}=\lambda_{o}=i \phi, \quad \omega \in \Omega .
\end{gathered}
$$

Note that if $i=0$, trades are efficient and if $i>0$, they are inefficient.

Using the envelope theorem and equations (7), (12), and (13), the marginal value of money satisfies

$$
V_{1}^{m}=\int_{\Omega}\left[\phi \alpha \varepsilon u^{\prime}\left(q_{b}\right) / c^{\prime}\left(q_{s}\right)\right] f(\omega) d \omega .
$$

Differentiating (14) shows that the value function is concave in $m$. 


\section{Stationary Equilibrium}

In period $t$, let $p_{3}$ denote the nominal price of goods in market 3 . It then follows that $\phi=1 / p_{3}$ is the real price of money. We study equilibria where end-of-period real money balances are time and state invariant:

$$
\phi M=\phi_{-1} M_{-1}=\phi_{0} M_{0} \equiv z, \quad \omega \in \Omega
$$

We refer to it as a stationary equilibrium. This implies that $\phi$ is not state dependent and so $\phi_{-1} / \phi=p_{3} / p_{3,-1}=M / M_{-1}=\gamma$. This effectively means that the central bank chooses a price path $p_{3}=\gamma p_{3,-1}$ in market 3 . Since $\phi$ is a jump variable and the only state variable that matters in market 3 is $M$, we can start the economy in steady state.

We now derive the symmetric stationary monetary equilibrium. In a symmetric equilibrium, all agents of a given type behave equally. Then, market clearing in market 2 implies

$$
q(\omega) \equiv q_{b}(\omega)=(s / n) q_{s}(\omega), \quad \omega \in \Omega,
$$

while in the credit market it implies that all buyers receive a loan of size

$$
l_{b}(\omega)=\frac{(1-n)\left[1+\tau_{1}(\omega) / \gamma\right] M_{-1}}{n}, \quad \omega \in \Omega
$$

In any monetary equilibrium, all real balances are spent in market 2 so market clearing implies

$$
(n / \alpha) q(\omega) c^{\prime}[(n / s) q(\omega)]=\left[1+\tau_{1}(\omega) / \gamma\right] z
$$

where $z=\phi M$ is the real stock of money. It follows from (18) that in binding states $q(\omega, z)<$ $q^{*}(\omega)$, where $q(\omega, z)$ is an increasing function of $z$. In nonbinding states, we have $q(\omega, z)=q^{*}(\omega)$, where $q^{*}(\omega)$ solves $(2)$.

Finally, use (4) to eliminate $V_{1}^{m}$ and (16) to eliminate $q_{s}$ from (14). Then, multiply the resulting expression by $M_{-1}$ to get

$$
\frac{\gamma-\beta}{\beta}=\int_{\Omega}\left\{\frac{\alpha \varepsilon \mathcal{u}^{\prime}[q(\omega, z)]}{c^{\prime}[(n / s) q(\omega, z)]}-1\right\} f(\omega) d \omega .
$$

We can now define the equilibrium as the value of $z$ that solves (19). The reason is that once the equilibrium stock of money is determined, all other endogenous variables can be derived.

\section{DEFINITION 1. A symmetric monetary stationary equilibrium is a $z$ that satisfies (19).}

Before moving on to stabilization policy, it is important to note that there are two nominal interest rates in our model. First, there is the interest rate paid on a riskless, one-period nominal bond issued in market 3 and redeemed in the following market 3 (quasi-linearity means the agents are risk neutral). Although such a bond is never traded, we can price it and its interest rate is given by $1+i_{3}=\gamma / \beta=(1+\pi)(1+\rho)$, where $\pi$ is the steady-state inflation rate from $t$ market 3 to $t+1$ market 3 and $\rho$ is the time rate of discount. Thus, the right-hand side of (19) corresponds to this nominal interest rate. The second nominal interest rate in the model is the state-contingent 
rate occurring in the market 1 financial market, $i(\omega)$. This is the nominal interest rate controlled by the central bank to stabilize the shocks. Thus, using (12) we can write (19) as

$$
i_{3}=\int_{\Omega} i(\omega) f(\omega) d \omega
$$

which is just an arbitrage condition between market 3 bonds and money. In short, by holding a unit of money, an agent gives up the "long-term" interest rate $i_{3}$ but earns the expected nominal interest rate $i(\omega)$ in state $\omega$ in market 1 (either by depositing the unit of money if it is not needed or by avoiding having to borrow a unit of money in market 1). Thus, (19) equates the nominal return of a market 3 bond to the expected nominal rate on a market 1 bond.

\section{STABILIZATION POLICY}

The central bank's objective is to maximize the welfare of the representative agent. It does so by choosing the quantities consumed and produced in each state subject to the constraint that the chosen quantities satisfy the conditions of a competitive equilibrium. The policy is implemented by choosing state-contingent injections $\tau_{1}(\omega)$ and $\tau_{3}(\omega)$ accordingly.

The primal Ramsey problem facing the central bank is

$$
\max _{q(\omega), x} U(x)-x+\int_{\Omega}\{n \varepsilon u[q(\omega)]-(s / \alpha) c[(n / s) q(\omega)]\} \times f(\omega) d \omega \quad \text { s.t. (19), }
$$

where the constraint facing the central bank is that the quantities chosen must be compatible with a competitive equilibrium. It is obvious that $x=x^{*}$, so all that remains is to choose $q(\omega)$.

Rather than doing a primal approach, conceptually we could use (12) to solve for $q(\omega)$ as a function of $i(\omega)$ and the shocks. We would then substitute those expressions into (21) to eliminate $q(\omega)$. The central bank's problem would then be to choose a menu of state-contingent nominal interest rates in market 1 subject to the arbitrage constraint (20) that the expected interest rate in market 1 is equal to the interest rate on a bond that trades from $t$ market 3 to $t+1$ market 3 . The central bank is assumed to take $i_{3}$ as given.

PROPOSITION 1. If $\gamma=\beta, i_{3}=0$, and the optimal policy is $i(\omega)=0$ with $q(\omega)=q^{*}(\omega)$ for all states.

According to Proposition 1, if $\gamma=\beta$ is feasible, the central bank should implement the Friedman rule $i(\omega)=0$ for all states. For $\gamma=\beta$, the rate of return on money is equal to the time rate of discount, implying prices in market 3 fall at the rate $\beta$, which is the discount factor. In this case, agents can costlessly carry money across periods. Since the only friction in our model is the cost of holding money across periods, the Friedman rule eliminates it. So, agents can perfectly self-insure against all consumption risk. Consequently, there are no welfare gains from stabilization policies. $\underline{12}$ Alternatively, if the central bank were allowed to choose $i_{3}$, it would set it to zero as well.

Now consider the case in which the central bank is constrained (for some reason) such that $\gamma>\beta$ or $i_{3}>0$. For this case, we have the following result. 
PROPOSITION 2. If $\gamma>\beta, i_{3}>0$, then the optimal policy is $i(\omega)>0$ with $q(\omega)<q^{*}(\omega)$ for all states.

According to Propositions 1 and 2, unless $i(\omega)=0$ can be done for all states, it is optimal to never set $i(\omega)=0$. Hence, zero nominal interest rates should be an all-or-nothing policy. This says that the zero lower bound is never an issue in our model-if $\gamma=\beta$, then it is optimal to always be at the lower bound and if $\gamma>\beta$, it is optimal to never hit the lower bound.

Why does the central bank never choose $i(\omega)=0$ for any state if $\gamma>\beta$ ? Whenever $\gamma>\beta$, $i_{3}>0$ and so there is an implicit opportunity cost to carry money across periods. Consequently, agents economize on cash balances. In the absence of policy intervention, this would imply that in some states, agents would have enough cash to buy the first-best quantity of goods $q^{*}(\omega)$, while in other states, their cash holdings constrain their spending such that $q(\omega)<q^{*}(\omega)$. This creates an inefficiency of consumption across states that stabilization policy can overcome. To see this, consider two states $\omega, \omega^{\prime} \in \Omega$ with $i(\omega)=0$ implying $q(\omega)=q^{*}(\omega)$ and $i\left(\omega^{\prime}\right)>0$ implying $q\left(\omega^{\prime}\right)$ $<q^{*}\left(\omega^{\prime}\right)$. Then, the first-order loss from decreasing $q(\omega)$ is zero, while there is a first-order gain from increasing $q\left(\omega^{\prime}\right)$. This gain can be accomplished by increasing $i(\omega)$ and lowering $i\left(\omega^{\prime}\right)$ such that the expected nominal interest rate in market 2 is unchanged. Thus, the central bank's optimal policy is to smooth interest rates across states.

For the remainder of the paper, we will study the behavior of stabilization policy under the condition that $\gamma>\beta$ and $i_{3}>0$ in order to understand how the central bank responds to the individual shocks.

\section{DISCUSSION}

In this section, we discuss how stabilization policy works in our economy and why stabilization policy requires control of price expectations. We then explore the gains from optimal stabilization by comparing the allocations under the optimal policy with the one when the central bank is passive. Finally, we discuss a benchmark with "sticky" prices.

\section{Liquidity and Inflation Expectation Effects}

The optimal stabilization policy in our model works through a liquidity effect. For this effect to operate, the central bank must control inflation expectations by choosing a price path in market 3. Without it, injections in the first market simply change price expectations and the nominal interest rate as predicted by the Fisher equation.

Under our proposed policy, the money stock as measured at the end of market 3 grows at the rate $M_{t}=\gamma M_{t-1}$, where $\gamma>\beta$ is fixed. In a stationary equilibrium, we assume that real balances measured in market 3 prices are constant, $\phi_{t} M_{t}=\phi_{t-1} M_{t-1}=z$, where $z$ is state independent. Recalling that $\phi_{t}=1 / p_{3, t}$, since $\tau_{1}(\omega)+\tau_{3}(\omega)=0$, we have that

$$
p_{3, t}=\frac{M_{t}}{M_{t-1}} p_{3, t-1}=\gamma p_{3, t-1} .
$$

Thus, by committing to this price path for prices in market $3, p_{3, t}$ is pinned down by the growth rate of the money stock and last period's price. Hence, at the beginning of market 1 , agents 
know what the price of goods will be at the end of the period. With $\gamma>\beta$, buyers will always be constrained by their real money balances, since the cost of holding money is not zero. Combining (18), (22), and the expression above for $p_{3, t}$ yields the quantities that can be purchased in market 2:

$$
q(\omega)=(\alpha / n)\left[1+\tau_{1}(\omega) / \gamma\right] M_{-1} / p_{3,-1}
$$

It is clear from this expression that the size of the monetary injection in market $1, \tau_{1}(\omega)$, will affect the quantity of goods purchased even though market 2 prices are perfectly flexible. Why is this? In market 2 , sellers accept money based on its purchasing power in market 3 , which is when they will spend it. Thus, any injection into market 1 that is unwound in market 3 does not cause inflation ( $\gamma$ does not depend on $\tau_{1}(\omega)$ ). As a result, sellers are willing to sell the same quantity at the existing market 2 price, $p_{2}$, even though the nominal money stock is higher in market 2 . From the buyers' point of view though, this implies that real balances are higher in market 2 and thus they can acquire more goods.

Alternatively, one can think of this as a liquidity effect from the monetary injection. This can be seen by substituting the expression for $q(\omega)$ above into (12):

$$
i(\omega)=\frac{\alpha \varepsilon u^{\prime}\left\{(\alpha / n)\left[1+\tau_{1}(\omega) / \gamma\right] M_{-1} / p_{3,-1}\right\}}{c^{\prime}\left\{(\alpha / s)\left[1+\tau_{1}(\omega) / \gamma\right] M_{-1} / p_{3,-1}\right\}}-1>0, \quad \omega \in \Omega
$$

For a given realization of shocks, the right-hand side of this expression is decreasing in $\tau_{1}(\omega)$. What is the intuition for this? If $\tau_{1}(\omega)>0$, then the central bank is injecting liquidity into market 1 . This has two effects. First, buyers now have more real balances and need to borrow less. Thus, the demand for loans declines. Second, sellers have more real balances as well, which they deposit in the bank. This increases the supply of loans. As a result, the nominal interest rate is bid down. Again, this only works because all agents expect this injection to be unwound in market 3 , leaving the real value of money in market 3 unchanged.

What happens if the central bank never undoes the state-contingent injections of market 1 ? In this case, $\tau_{3}(\omega)=0$ for all $t$ and $\omega \in \Omega$. We can then state the following:

PROPOSITION 3. Assume that $\tau_{3}(\omega)=0$ for all $\omega \in \Omega$. Then, changes in $\tau_{1}(\omega)$ have no real effects and any stabilization policy is ineffective.

If the central bank does not reverse the state-contingent injections of the first market, the price of goods in market 2 changes proportionately to changes in $\tau_{1}(\omega)$. Consequently, the real money holdings of the buyers are unaffected and consumption in market 2 does not react to changes in $\tau_{1}(\omega)$. Such a policy only affects the expected nominal interest rate. To see this, note that the gross growth rate of the money supply in this case is $\gamma_{t}=\tau_{1}(\omega)+\tau+1$. Then substitute this and (22) into the constraint of the central bank problem to get

$$
\frac{\tau_{1}(\omega)+\tau+1-\beta}{\beta}=\int_{\Omega} i(\omega) d F(\omega) .
$$


An increase in $\tau_{1}(\omega)$ increases the expected nominal interest rate. This is simply the inflation expectation effect from the Fisher equation.

An example. To illustrate how the stabilization policy works when $\gamma>\beta$, consider a simple example in which the only shock is the intensive margin demand shock $\varepsilon$. Let $\varepsilon$ be uniformly distributed and assume $\alpha \underline{\varepsilon}>1$. Preferences are $u(q)=1-\exp ^{-q}$ and $c(q)=q$. With these functions, the first-order conditions for the central bank yields $\underline{13}$

$$
\alpha \varepsilon \exp ^{-q}=\frac{n}{n-\alpha \lambda}
$$

where $\lambda$ is the multiplier on the constraint in (19). Substituting this expression in the central bank's constraint (19), we have

$$
\frac{\gamma-\beta}{\beta}=\int_{\underline{\varepsilon}}^{\bar{\varepsilon}} \frac{\alpha \lambda}{n-\alpha \lambda} f(\varepsilon) d \varepsilon=\frac{\alpha \lambda}{n-\alpha \lambda} .
$$

Solving for $\lambda$ and substituting back into (23) yields

$$
q(\varepsilon)=\ln \alpha \varepsilon-\ln (\gamma / \beta)=q^{*}(\varepsilon)-\ln (\gamma / \beta),
$$

where $q(\varepsilon)$ is increasing in $\varepsilon . \underline{14}$ Furthermore,

$$
i(\omega)=\frac{\gamma-\beta}{\beta} .
$$

Note that this example generates perfect interest rate smoothing by the central bank. When demand for goods (and loans) increases, the central bank accommodates this higher demand by injecting funds into the market 1 financial market, thereby keeping interest rates constant. This allows buyers to consume more. While smoothing interest rates is a general property of our model, perfect smoothing is a special case resulting from the functional forms used.

From the buyer's budget constraint we have

$$
q(\varepsilon)=\frac{\alpha\left[\gamma+\tau_{1}(\varepsilon)\right] z}{n \gamma} .
$$

Since $z$ is not state dependent, taking the ratios of (25) for all $q(\varepsilon)$, relative to $q(\underline{\varepsilon})$ gives

$$
q(\varepsilon)=\frac{1+\tau_{1}(\varepsilon) / \gamma}{1+\tau_{1}(\underline{\varepsilon}) / \gamma} q(\underline{\varepsilon}) .
$$

Since the transfers are nominal objects, there is one degree of freedom in $\tau_{1}(\varepsilon)$, so let $\tau_{1}(\underline{\varepsilon})=0$. This implies that in the state in which buyers have the lowest demand for goods, the central bank does not inject any cash. Thus,

$$
z=(n / \alpha)[\ln \alpha \underline{\varepsilon}-\ln (\gamma / \beta)]
$$

and using (24) and (26) gives us the sequence of transfers that implements this desired allocation: 


$$
\tau_{1}(\varepsilon)=\gamma\left[\frac{\ln \alpha \varepsilon-\ln (\gamma / \beta)}{\ln \alpha \underline{\varepsilon}-\ln (\gamma / \beta)}-1\right]>0 \text { for all } \varepsilon>\underline{\varepsilon},
$$

so $\tau_{1}(\varepsilon)>0$ for all $\varepsilon>\underline{\varepsilon}$ and increasing in $\varepsilon$. Thus, the higher is demand for goods, the larger is the injection needed to finance this increased consumption.

\section{The Inefficiency of a Passive Policy}

What are the inefficiencies arising from a passive policy? In order to study this question, we now derive the allocation when the central bank follows a policy where the injections are not state dependent, that is, $\tau_{1}(\omega)=\tau_{3}(\omega)=0$, and compare it with the central bank's optimal allocation. We do so under the assumption that $\gamma>\beta$ or $i_{3}>0$. The fact that the central bank is assumed to generate an inflation rate above that predicted by the Friedman rule is intended to capture various constraints on the central bank's ability to deflate, such as seigniorage concerns, inflation targets, etc. Our main objective is to better understand how optimal stabilization affects the allocation across states relative to doing nothing. $\underline{\underline{15}}$

Intensive margin demand shocks. To study $\varepsilon$ shocks, we assume that $\alpha, n$, and $s$ are constant. It then follows that $\omega=\varepsilon$. Note that the first-best quantity $q^{*}(\varepsilon)$ is strictly increasing in $\varepsilon$.

PROPOSITION 4. For $\gamma \geq 1$, a unique monetary equilibrium exists with $q<q^{*}(\varepsilon)$ for $\varepsilon>\tilde{\varepsilon}$ and $q=q^{*}(\varepsilon)$ for $\varepsilon<\tilde{\varepsilon}$, where $\tilde{\varepsilon} \in[0, \bar{\varepsilon}]$. Moreover, $d \tilde{\varepsilon} / d \gamma<0$.

With a passive policy, buyers are constrained in high marginal utility states but not in low states. If $\gamma$ is sufficiently high, buyers are constrained in all states. Note that with a passive policy $d q / d \varepsilon>0$ for $\varepsilon \leq \tilde{\varepsilon}$ and $d q / d \varepsilon=0$ for $\varepsilon>\tilde{\varepsilon}$. For $\varepsilon \leq \tilde{\varepsilon}$, buyers have more than enough real balances to buy the efficient quantity. So, when $\varepsilon$ increases, they simply spend more of their money balances. For $\varepsilon>\tilde{\varepsilon}$, buyers are constrained. So, when $\varepsilon$ increases, the demand for loans increases but the supply of loans is unchanged, so no additional loans can be made. Thus, the interest rate simply increases to clear the credit market.

How does this allocation differ from the one obtained by following an active policy? We illustrate the differences in Figure 1 for a linear cost function. Figure 1 illustrates how the allocation resulting from a passive policy differs from the one obtained under an active policy. The dashed curve represents the first-best quantities $q^{*}(\varepsilon)$. The curve labeled "Passive $q$ " represents equilibrium consumption under a passive policy and the curve labeled "Active $q$ " consumption when the central bank behaves optimally. The central bank's optimal choice is strictly increasing in $\varepsilon$ for any cost function.

For concreteness, consider the functional forms used in the example above. In this case, we obtain

$$
\begin{gathered}
q(\varepsilon)=\ln \alpha \varepsilon, \quad i(\varepsilon)=0 \quad \text { for } \varepsilon \leq \tilde{\varepsilon} \\
q(\varepsilon)=\ln \alpha \tilde{\varepsilon}, \quad i(\varepsilon)=\frac{\varepsilon}{\tilde{\varepsilon}}-1 \quad \text { for } \varepsilon \geq \tilde{\varepsilon} \\
\tilde{\varepsilon}=\bar{\varepsilon}+\frac{\gamma-\beta}{\beta}(\bar{\varepsilon}-\underline{\varepsilon})-\sqrt{\left[\bar{\varepsilon}+\frac{\gamma-\beta}{\beta}(\bar{\varepsilon}-\underline{\varepsilon})\right]^{2}-\bar{\varepsilon}^{2},}
\end{gathered}
$$




\section{Figure 1}

\section{Marginal Utility Shocks}

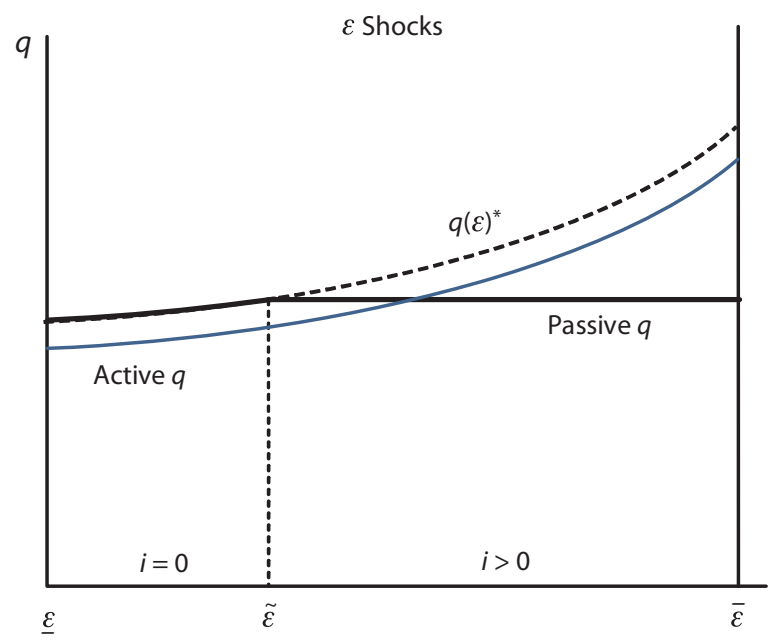

Figure 2

Shocks to the Number of Buyers

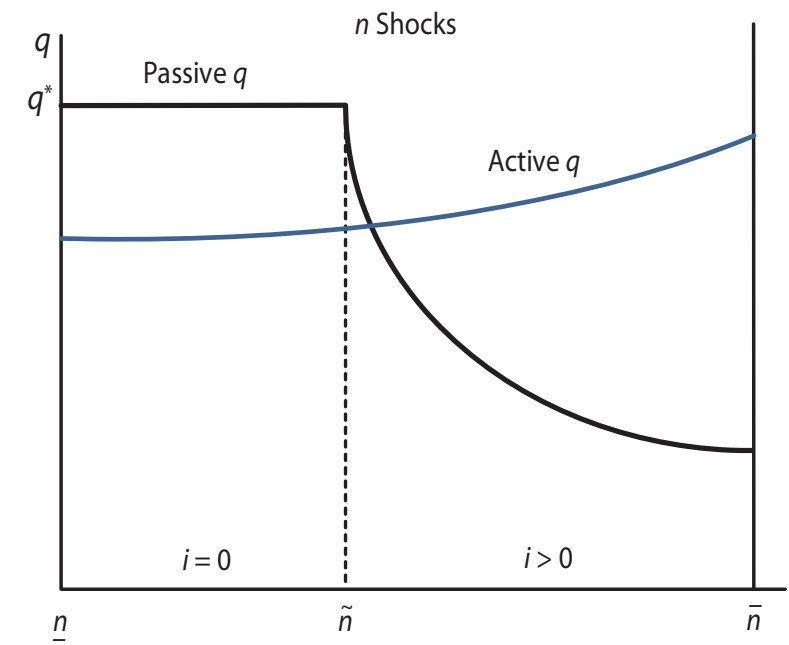

where $\bar{\varepsilon}>\tilde{\varepsilon} \geq \underline{\varepsilon}$ for sufficiently low values of $\gamma$. This example reflects what is happening in Figure 1. The central bank chooses to reduce consumption from the first best in low demand states in order to increase it in higher demand states. Furthermore, whereas the optimal policy has a constant nominal interest, the passive policy generates a procyclical nominal interest rate due to high demand for lending in high $\varepsilon$ states. Finally, note that at the Friedman rule, $\gamma=\beta$, the critical cutoff is the upper bound on $\varepsilon$, that is, no buyers are constrained by their money balances and the first-best allocation is achieved.

Extensive margin demand shocks. For the analysis of shocks to $n$, we assume that $\alpha, \varepsilon$, and $s$ are constant. Note that the first-best quantity $q^{*}(n)$ is nonincreasing in $n$.

PROPOSITION 5. For $\gamma \geq 1$, a unique monetary equilibrium exists with $q=q^{*}(n)$ if $n \leq \tilde{n}$ and $q<q^{*}(n)$ if $n>\tilde{n}$, where $\tilde{n} \in[0, \bar{n}]$. Moreover, $d \tilde{n} / d \gamma<0$.

With a passive policy buyers are constrained when there are many borrowers (high $n$ ) and are unconstrained when there are many creditors (low $n$ ). Since $d \tilde{n} / d \gamma<0$, the higher is the inflation rate, the larger is the range of shocks where the quantity traded is inefficiently low. Note that for large $\gamma$ we can have $\tilde{n} \leq \underline{n}$, which implies that $q<q^{*}(n)$ in all states.

As shown earlier, with an active policy buyers never consume $q^{*}$, and with linear cost the central bank wants $q$ to be increasing in $n . \underline{16}$ This is just the opposite from what happens when the central bank is passive. With a passive policy, buyers consume $q=q^{*}$ in low $n$ states and $q<q^{*}$ in high $n$ states. Moreover, $q$ is strictly decreasing in $n$ for $n>\tilde{n}$. These differences are also reflected in the nominal interest rates. With an active policy, the nominal interest rate is strictly positive in all states and decreasing in $n$. In contrast, with a passive policy, the nominal interest rate is $i=0$ for $n \leq \tilde{n}$ and $i=\varepsilon \alpha u^{\prime}(q)-1 \geq 0$ for $n>\tilde{n}$, and increasing in $n$. These effects are illustrated in Figure 2. 
What is the role of the credit market? With a linear cost function and no credit market, the quantities consumed are the same across all $n$-states since buyers can only spend the cash they bring into market 1 , which is independent of the state that is realized. In contrast, with a credit market, idle cash is lent out to buyers. This makes individual consumption higher on average but also more volatile. The reason is that when $n$ is high, demand for loans is high and the supply of loans is low. This pushes up the nominal interest rate and decreases individual consumption. The opposite occurs when $n$ is low.

Finally, we have also derived the equilibrium under a passive policy for the extensive, $s$, and the intensive, $\alpha$, supply shocks. The results and figures are qualitatively the same and we therefore do not present them here. They typically involve a cutoff value such that the nominal interest rate is zero either above or below this value. These derivations are available by request.

\section{CONCLUSION}

In this paper, we have constructed a dynamic stochastic general equilibrium model where money is essential for trade and prices are fully flexible. Our main result is that if the central bank engages in price-level targeting, it can successfully stabilize short-run aggregate shocks to the economy and improve welfare. By adopting a price-level target, the central bank is able to manage inflation expectations, which enable it to pursue welfare-improving stabilization policies. If it does not adhere to the targeting price path, stabilization attempts are ineffective. Monetary injections simply raise price expectations and the nominal interest rate as predicted by the Fisher equation. By adhering to the targeted price path, the optimal policy works through a liquidity effect-the central bank reduces the nominal interest rate via monetary injections to expand consumption and output.

There are many extensions of this model that would be interesting to pursue. For example, why would the optimal monetary policy involve $\gamma>\beta$ ? Existing search theoretic models of money suggest there may be a trade-off between the extensive and intensive margins that induces the central bank to create anticipated inflation. 17 Another issue is to assess the behavior of the model quantitatively. In short, what are the welfare gains from stabilizing shocks? Furthermore, as our example showed, nominal interest rate smoothing may be optimal. This stands in contrast to many NK models whereby the nominal interest rate is quite volatile. Thus, it would be interesting to see what a fully calibrated version of our model predicts for the volatility of the nominal interest rate. We leave these questions for future research.

\section{NOTES}

1 See, for example, Woodford (2003) Chaps. 1 and 7. Also see Clarida, Galí, and Gertler (1999, p. 1663).

$\underline{2}$ The frictions that make money essential are information frictions regarding individual trading histories, public communication frictions of individual trading outcomes, and lack of enforcement. Note that these frictions have nothing to do with particular goods, locations, individuals, or pricing protocols. Nor does it imply that money saves "time" as in a shopping time model.

3 By essential we mean that the use of money expands the set of allocations (Kocherlakota, 1998, and Wallace, 2001).

4 Competitive pricing in the Lagos-Wright framework is a feature in Rocheteau and Wright (2005) and Berentsen, Camera, and Waller (2005). 


\section{Berentsen and Waller}

$\underline{5}$ As in Lagos and Wright (2005), these assumptions allow us to get a degenerate distribution of money holdings at the beginning of a period. The different utility functions $U($.) and $u($.) allow us to impose technical conditions such that in equilibrium all agents produce and consume in the last market.

$\underline{6}$ One can think of agents being able to barter perfectly in this market. Obviously in such an environment, money is not needed.

$\underline{7}$ One possibility would be that agents require a particular "tool" to be able to consume in market 2 . This tool can then be used as collateral against loans in market 1 so that for sufficiently high discount factors repayment occurs with probability one. In Berentsen, Camera, and Waller (2007), we derive the equilibrium when the only punishment for strategic default is exclusion from the financial system in all future periods.

$\underline{8}$ There is a difference between lump-sum taxation and loan repayment. Voluntary loan repayment can be supported with reputational strategies (see, e.g., Berentsen, Camera, and Waller, 2007). The reason is that default results in exclusion from financial markets and the loss of future benefits. In contrast, taxes typically finance public goods for which exclusion is not possible; thus, taxes must necessarily be forced on individual agents by society.

9 Lucas (1990) employs a similar process for the money supply so that changes in nominal interest rates result purely from liquidity effects and not changes in expected inflation.

10 We think this characterizes what happened prior to, during, and after the crisis-the economy was operating "normally," then hit a period where liquidity frictions arose, and then the economy began operating normally again. In our model, these periods occur determininistically rather than stochastically. It would be interesting to study the case where the liquidity frictions occurring in market 2 occur randomly and not deterministically.

11 Woodford (2003, p. 75, footnote 9) makes a similar argument.

12 Ireland (1996) derives a similar result in a model with nominal price stickiness. He finds that at the Friedman rule there is no gain from stabilizing aggregate demand shocks.

$\underline{13}$ With these utility and cost functions, the central bank's second-order condition is satisfied.

14 Since the Inada condition does not hold for this utility function, $q(\underline{\varepsilon})=0$ when $\gamma=\beta \alpha \underline{\varepsilon}$. Thus, for all $\beta \leq \gamma<\beta \alpha \underline{\varepsilon}$, an equilibrium exists. For $\gamma \geq \beta \alpha \underline{\varepsilon}$, no monetary equilibrium exists.

15 Two comments are in order. First, a more thorough analysis should explain why $\gamma>\beta$ is not a policy choice of the central bank. Many have argued that if $\gamma<1$, then the central bank must resort to lump-sum taxation to extract money from the economy. It may be the case that the institutional structure does not allow taxation by the central bank. Hence, the case with $\gamma \geq 1>\beta$ is a reflection of this. Second, if $\gamma>\beta$, then fiscal policy could be used to provide a state-contingent production subsidy financed by lump-sum taxation in market 3 to eliminate any distortions. It is debatable whether this type of state-contingent fiscal policy is more feasible than state-contingent monetary policy in practice, as is the use of lump-sum taxes. Furthermore, if distortionary taxation is used, then it may be optimal to set $\gamma>\beta$ yet have a production subsidy that does not eliminate the distortion caused by $\gamma>\beta$ (see Aruoba and Chugh, 2008). In this case, our results would go through.

16 This can be shown by differentiating the central bank's first-order condition with respect to $n$ to find $\partial q / \partial n$.

17 Berentsen and Waller (2009a) pursue this issue and show that the central bank may not choose $\gamma=\beta$ under the optimal policy.

\section{REFERENCES}

Aruoba, S. Borağan and Chugh, Sanjay. “Money and Optimal Capital Taxation.” Unpublished manuscript, University of Maryland, 2008.

Berentsen, Aleksander; Camera, Gabriele and Waller, Christopher. "The Distribution of Money Balances and the NonNeutrality of Money." International Economic Review, 2005, 46(2), pp. 465-87.

Berentsen, Aleksander; Camera, Gabriele and Waller, Christopher. "Money, Credit and Banking." Journal of Economic Theory, July 2007, 135(1), pp. 171-95.

Berentsen, Aleksander; Rocheteau, Guillaume and Shi, Shouyong. "Friedman Meets Hosios: Efficiency in Search Models of Money." Economic Journal, 2007, 117(516), pp. 174-95. 
Berentsen, Aleksander and Waller, Christopher. "Optimal Stabilization Policy with Endogenous Firm Entry." Unpublished manuscript, University of Notre Dame, 2009a.

Berentsen, Aleksander and Waller, Christopher. "Price Level Targeting and Stabilization Policy." Working Paper No. 2009-033B, Federal Reserve Bank of St. Louis, October 2009b; http://research.stlouisfed.org/wp/2009/2009-033.pdf.

Clarida, Richard H.; Galí, Jordi and Gertler, Mark L. "The Science of Monetary Policy: A New Keynesian Perspective." Journal of Economic Literature, 1999, 37, pp. 1661-707.

Fuerst, Timothy S. "Liquidity, Loanable Funds and Real Activity." Journal of Monetary Economics, February 1992, 29, pp. 3-24.

Grossman, Sanford and Weiss, Laurence. "A Transactions-Based Model of the Monetary Transmission Mechanism." American Economic Review, December 1983, 73(5), pp. 871-80.

Ireland, Peter N. "The Role of Countercyclical Monetary Policy." Journal of Political Economy, August 1996, 104(4), pp. 704-23.

Kocherlakota, Narayana R. "Money Is Memory." Journal of Economic Theory, August 1998, 81(2), pp. 232-51.

Kocherlakota, Narayana R. "Money: What's the Question and Why We Care about the Answer." Staff report, Federal Reserve Bank of Minneapolis, 2001.

Lagos, Ricardo and Wright, Randall. "A Unified Framework for Monetary Theory and Policy Analysis." Journal of Political Economy, June 2005, 113(3), pp. 463-84.

Lucas, Robert. “Liquidity and Interest Rates." Journal of Economic Theory, April 1990, 50(2), pp. 237-64.

Rocheteau, Guillaume and Wright, Randall. "Money in Search Equilibrium, in Competitive Equilibrium, and in Competitive Search Equilibrium." Econometrica, January 2005, 73(1), pp. 175-202.

Wallace, Neil. "Whither Monetary Economics?" International Economic Review, November 2001, 42(4), pp. 847-69.

Woodford, Michael. Interest and Prices: Foundations of a Theory of Monetary Policy. Princeton, NJ: Princeton University Press, 2003. 
